\title{
The Anatomy of Employee involvement and Internal branding and their Impact on the Emotional Intelligence of employees: Evidence from the nursing staff hospital sector of Pakistan.
}

\author{
Fatima Nayyar Khan, Professor Dr. Hamayoun Naeem \\ Foundation University of Engineering \& Management Sciences, New Lalazar, Rawalpindi
}

\begin{abstract}
Employee involvement and internal branding is a very important concept in organizations nowadays especially when organizations desire more profitability as well as stability to sustain in a competitive environment. Motivating employees to give in input in decision making does increase the performance and effectiveness of the organization thus adding to the creativity and innovative level of the employees. On top of that employees who are more involved in decisions and are motivated they have relatively more stability as far as their emotions are concerned like anger frustration etc. On the basis of various studies conducted the relationship between employee involvement, internal branding and emotional intelligence of employees was examined. The sample was taken from two hospitals from the twin cities Rawalpindi and Islamabad and research primary focused on the nurses of the two hospitals the first one was Al-Shifa Eye Hospital Rawalpindi and the second one was Shifa International Medical Hospital Islamabad both are the private sectors of Pakistan. Data that was gathered for these respective variables that is employee involvement; internal branding and emotional intelligence were analyzed and played an important role in the gathering of data respectively.
\end{abstract}

\section{Introduction}

When an organization of any kind desires to establish a positive working atmosphere for its employees that is exceptional decision making, working on innovative ideas, efficiency and effectiveness of work then the organization should focus all its attention to the needs of its most valuable assets that is its employees in this case the nursing stuff working in the hospital (Cadman \& Brewer, 2001). This will make the organization move forward with greater efficiency, more commitment and greater productivity and thus will lead the organization towards more profitability and success in the future. (Morland, 2001). That's where the concept of employee involvement is introduced in any organization each individual in an organization is considered as an incomparable person and each and every individual in the organization is directly or indirectly affecting the organization reach its aim or objective (Kahn, 1990; Kanungo,1979; Lawler). Each employees input is solicited and it is valued by the management. The organization realizes how important it is for employees to take part in decision making as this leads to higher level of creativity and innovativeness thus resulting in overall effectiveness of the organization (Lodahl \& Kejner, 1965; p.24). Here our main focus is on the nursing staff of the hospitals. The involvement of nurses in decision making are very important as they are the main assets of the hospital without them a single procedure cannot be completed efficiently in an hospital that's why their assistance is so important for doctors. Secondly, what we should realize is that how the input of nurses can lead to higher creativity and innovativeness levels which can overall add to the organization effectiveness (Lawler, 1971; Mohrman et al., 1989). On the other hand the concept of internal branding is also considered very important as far the organization effectiveness is concerned. Internal branding is promoting your organization from inside out that is providing your employees such as the nursing staff with different compensation and benefits so that you can align their goals to meet one organization objective (Carmeli, 2003). It is very important to align your employees such as on one path that is the main objective of the organization only if the employees are internally on one path and believe in their organization brand only then they will be able to promote their brand outside the organization as well (Cadman \& Brewer, 2001). In this paper we are clearly going to check the impact of these two factors employee involvement and internal branding on the emotional intelligence level of employees. Emotional intelligence is regarded as one's ability to judge the emotions of others as well as control their own emotions like anger, frustration and also controlling and regulating the emotions of others, and of groups in a respective organization (Lawler, 1971; Mohrman et al., 1989). Here again nurses play a very important part as it is very essential for the nursing staff to be very emotionally stable as their stability may affect the life of their patients and many other (Morland, 2001). Even though keeping your emotions stable is important in every organization for its effectiveness but it is especially important in the hospital sectors as your emotions are directly linked to the life of other people (Lodahl \& Kejner, 1965; p.24). We have conducted this study just to analyze whether a relationship co-exists between employee involvement, internal branding and emotional intelligence of the employees that is the nursing staff of both the Al-Shifa Hospitals. 


\section{Problem Under Study}

On the basis of the above discussion and literature review the author plans to analyze the effect of job involvement and internal branding on the emotional intelligence of the employees in the health sector of the private hospitals of Pakistan.

\section{Originality Of The Study}

The main focus of the research here is the impact of employee involvement and internal branding on the emotional intelligence of employees in the private sector of Pakistan. There is a knowledge gap here as no such research has been conducted in Pakistan before also even though a lot of work has been conducted on emotion intelligence and employee involvement which are only two factors of our research other factor such as internal branding is relatively a newer concept that has never been explored thoroughly especially in Pakistan. The third reason is that even though a lot of research has been conducted previously on hospitals but the nursing staffs is the area which has never been fully explored thoroughly in Pakistan. This research conducted fills the gap and has an influential effect on the knowledge of body as well as it is a guideline provided to other researchers for the work they want to conduct regarding these concepts in the future.

\section{Applied Aspect}

This research can be applied practically as well like the output of the study can be provided to the management of the hospital on how can they involved their nurses in decision making which can lead to higher productivity levels. This research can also help hospitals gain a different perspective on the importance of nurses' involvement in decision making, internal branding and its impact on their emotion intelligence.

Listed below are the objectives of the research:

1. To observe the level of individual involvement and internal branding in private health sector of Pakistan.

2. To check the impact of emotional intelligence in the same area.

3. To observe if there is any relationship between the three variables, that is employee involvement, internal branding (independent) and emotional intelligence (dependent)

\section{Literature Review}

There has been research associating E.I with key skills among nursing staff (Cadman \& Brewer, 2001) with interpersonal skills among managers (Morland,2001) and some components of EI have been found to be strongly associated with transformational leadership behaviours (Beadle, 2000). Individuals who were highly committed and involved in decision making were most likely to move towards organizational goals and were less likely to be turned out of the organization (Kahn, 1990; Kanungo, 1979; Lawler, 1986; Pfeffer, 1994). They will never get involved in a specific job which will only full fill their own self-interest but they will also get involved because they will let their inner emotions play a role in their involvement in different decision making process. When an individual gets highly involved in a specific job it is often due to his/her emotional needs. Individuals are very sociable who through job involvement gains the emotional experience as well (Carmeli, 2003). Thus, it seems that these individuals should consider their career as success. They are emotionally involved with their job and identify with it. Therefore, those employees who are high in E.I. should be high in job involvement. He went on to note that not enough research has been conducted to understand what really creates job involvement. Lawler studies focuses on the advantages that can come out from carefully analysed employee involvement programs for this to work employee involvement needs to be directly linked to other human resource activities of the firm such as benefits provision, motivational compensation packages and productivity appraisals (Lawler 1971, Mohrman et al. 1989) so from this it can be analysed that more an individual is satisfied by his/her job as far as the equity and generosity is concerned the more that person will be involved in his/her job.(Lodahl \& Ejner, 1965; pg 24). Internal branding is relatively a newer concept in human resource and it may have originated from some marketing terminology that only if the inner brand of the organization like the employees are aligned on one goal, objective through different planned motivational activities then they will be able to promote their brand outside the organization as well thus resulting in effectiveness (Judson, Gorchels \& Aurand, 2006; Punjaisri, Wilson \& Evanschitzky, 2008).

The above literature review indicates the following:

1. Research indicates that emotional intelligence plays an important role in the employee involvement and commitment of the employees.

2. Research indicates employee do not get committed to a certain job only for their own self interest but also because their inner emotions play an important role.

3. Internal branding can also impact employee commitment towards the organization as well as their motivational levels. 
This research is filling the knowledge gap because no previous research has been conducted on this topic especially on the nursing sector of Pakistan. Secondly, the concept of internal branding is explored which has never been explored thoroughly.

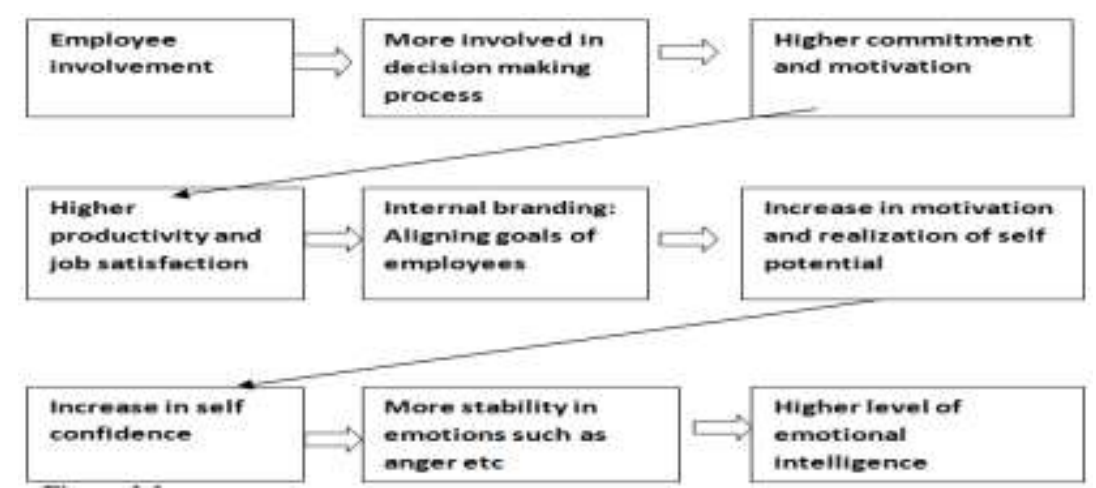

Figure 1.1

Employee involvement and internal branding and their impact on emotional intelligence of employees: A conceptual model.

Source: Researcher's Own Processing.

\section{Theoretical Framework And Hypothesis}

Following theoretical framework has been devised for the making of hypothesis (Figure 1). The hypothesis as follows:

$\mathbf{H}_{\mathbf{1}}$ : Increase in employee involvement leads to increase in emotional intelligence of employee.

$\mathbf{H}_{\mathbf{0}}$ : There is no relationship between employee involvement and emotional intelligence of employees.

$\mathbf{H}_{2}$ : Increase in internal branding leads to increase in emotional intelligence of employees.

$\mathbf{H}_{\mathbf{0}}$ : There is no relationship between internal branding and emotional intelligence of employees.

\section{Methodology}

The present work consisted of two leading well known hospitals of Pakistan. Al-Shifa Eye Hospital emphasize on employee involvement and internal branding within their employees. Other hospital was Shifa International Hospital Islamabad, a local private hospital whose main aim is promoting their brand within the organization and its employees.

\section{Sampling Procedure}

A group sample of 210 individuals or employees from the respective organization.

\begin{tabular}{|l|c|}
\hline \multicolumn{1}{|c|}{ Table 1: Sampling details } \\
\hline Al-Shifa Eye Hospital & Respondents \\
\hline Shifa International Hospital Islamabad & 100 \\
\hline Total & 110 \\
\hline Grand Total & 210 \\
\hline
\end{tabular}

\section{Technique Used For Data Gathering}

Twenty six items questionnaire was devised for the measurement of employee involvement and internal branding on emotional intelligence. Survey was adapted from the research of Lodahl and Kejner (1965) and (Lawler, 1971; Mohrman et al., 1989). Five item measurement scale was was used to observe. A five point Likert Scale was also adopted for the observation and analysis.

\section{Reliability of the Tool} reliability.

The SPSS version that was used was 20 while the reliability of the scale was 8.72 which was strong

\section{ANALYSIS OF DATA GATHERED}

Demographic Characteristics: Employees of Al-Shifa Eye Hospital and Shifa International Islamabad. 


\begin{tabular}{|c|c|c|}
\hline & Frequency & Percent \\
\hline \multicolumn{3}{|l|}{ Age } \\
\hline $20-25$ years & 27 & 12.9 \\
\hline $26-30$ years & 47 & 22.4 \\
\hline $31-35$ years & 69 & 32.9 \\
\hline $36-40$ years & 42 & 20.0 \\
\hline $\begin{array}{c}\text { Above } 40 \\
\text { years }\end{array}$ & 25 & 11.9 \\
\hline \multicolumn{3}{|l|}{ Gender } \\
\hline Male & 102 & 48.6 \\
\hline Female & 108 & 51.4 \\
\hline \multicolumn{3}{|l|}{$\begin{array}{l}\text { Marital } \\
\text { Status }\end{array}$} \\
\hline Married & 125 & 59.5 \\
\hline Unmarried & 85 & 40.5 \\
\hline \multicolumn{3}{|l|}{$\begin{array}{c}\text { Educational } \\
\text { Qualification }\end{array}$} \\
\hline $1-5$ & 55 & 26.2 \\
\hline $5-10$ & 88 & 41.9 \\
\hline FSC & 26 & 12.4 \\
\hline BA & 32 & 15.2 \\
\hline Diploma & 9 & 4.3 \\
\hline \multicolumn{3}{|l|}{ Experience } \\
\hline $0-2$ years & 10 & 4.8 \\
\hline $3-5$ years & 28 & 13.3 \\
\hline $6-8$ years & 63 & 30.0 \\
\hline $8-10$ years & 94 & 44.8 \\
\hline above 10 years & 15 & 7.1 \\
\hline \multicolumn{3}{|l|}{ Remuneration } \\
\hline $3000-5000$ & 63 & 30.0 \\
\hline $5000-10000$ & 18 & 8.6 \\
\hline $10000-12000$ & 62 & 29.5 \\
\hline $12000-14000$ & 26 & 12.4 \\
\hline above 14000 & 41 & 19.5 \\
\hline
\end{tabular}

Majority of the employees in Shifa International Islamabad were under the age of 40 years and were mostly in their thirties while in Shifa Eye Hospital majority of the employees were also under the age of 40 years. The male nurses working in Shifa International were 52 (47.3 per) and the female nurses were 58 (52.7 per) while in al Shifa Eye Hospital 50 were male (50 per) while 50 were female (50 per). In Shifa International majority of the employees were married (56.4 per) while the rest were single (43.6 per). In Shifa International majority of the nurses education was between 5-10 grade while some were diploma holders and some had passed their BA exam while in Shifa Eye Hospital majority of the employees education lied between 5 to 10 grade while rest were FSC passed or so. As far as the experience goes employees in both organizations had majority experience of 8 to 10 years. In Shifa International 40 per of the employee's salary ranged between 3000-5000 while in Shifa Eye Hospital 39 per of the employees' salaries ranged between 10000-12000.

Table 1: Employee Involvement and Emotional Intelligence

\begin{tabular}{lcccc}
\hline $\mathbf{R}$ & R2 & Ad.R2 & F Stat. & P value \\
\hline .533 & .284 & .272 & 23.017 & .000 \\
\hline
\end{tabular}

\section{Source: Researcher's Own Processing}

R-value

$\mathrm{R}$-value here emphasise on the correlation between employee involvement and emotional intelligence of the employees in both the organizations Shifa International Islamabad and Shifa Eye Hospital. For both the organizations $(\mathrm{r}=.5330)$ which further indicates positive correlation among two variables which are employee involvement and emotional intelligence.

$\mathbf{R}^{2}$ 
$\mathrm{R}^{2}$ is the coefficient of determination; the more the value is near to 1 the greater will be the reliability and accuracy of model. In this scenario for both of the organizations the $\mathrm{R}^{2}$ value is 0.284 which indicates greater accuracy between two variables such as employee involvement and emotional intelligence thus indicating a positive relationship between the two variables.

\section{Adjusted $\mathbf{R}^{2}$-Value}

An $\mathrm{R}^{2}$ adjusted value in this specific case points out the adjustments in $\mathrm{R}^{2}$ which shows the reality. Adjusted $\mathrm{R}^{2}$ values in both the organizations are 0.272 .

\section{F-Statistics}

If we study the $\mathrm{f}$ statistic for both the organization we can see that the model fitted is quite accurate.

\section{P-Value}

P-value (0.000) in this case is lower than $<\alpha(0.05)$ acknowledging the research hypothesis that greater the employee involvement in organization greater will be the emotional intelligence level of employees respectively. This also rejects our null hypothesis which indicates a negative relationship between two variables.

\begin{tabular}{lcccc}
\multicolumn{4}{l}{ Table 2: Internal Branding and Emotional } & Intelligence \\
\hline $\mathbf{R}$ & $\mathbf{R 2}$ & Ad.R2 & F Stat. & P value \\
.623 & .388 & .378 & 36.819 & .000 \\
\hline
\end{tabular}

$\mathbf{R}$ value

$\mathrm{R}$ value here indicates or emphasise on the correlation coefficient between internal branding and emotional intelligence of the employees in both the organizations Shifa International Islamabad and Shifa Eye Hospital. For both the organizations $(r=.623)$ which further indicates positive correlation among two variables which are internal branding and emotional intelligence.

$\mathbf{R}^{2}$

$\mathrm{R}^{2}$ is the coefficient of determination; the more the value is near to 1 the greater will be the reliability and accuracy of model in this scenario. In case of both the organizations the $\mathrm{R}^{2}$ value is 0.388 which indicates greater accuracy between two variables such as internal branding and emotional intelligence thus indicating a positive relationship between the two variables.

\section{Adjusted R2-Value}

An $\mathrm{R}^{2}$ adjusted value in this specific case points out the adjustments in $\mathrm{R}^{2}$ which shows the reality. Adjusted $\mathrm{R}^{2}$ values in both the organizations for internal branding and emotional intelligence is 0.378 .

\section{F-Statistics}

If we study the f statistic for both the organization we can see that the model fitted is quite accurate for all the variables under study.

\section{P-Value}

$\mathrm{P}$ value $(0.000)$ in this case is lower than $<\alpha(0.05)$ acknowledging the research hypothesis proposed that greater the internal branding in organization greater will be the emotional intelligence level of employees respectively. This also rejects our null hypothesis which indicates a negative relationship between the two variables.

\section{Discussion}

After analysing the results thoroughly it can be concluded that our regression results were in in accordance with our proposed hypothesis respectively. From these results $\mathrm{H}_{1}$ hypothesis is accepted similarly internal branding has a significant relationship with emotional intelligence so $\mathrm{H}_{2}$ is also accepted. While the null hypothesis for both the variables were rejected as there was proven to be a positive relationship between all the variables rather than a negative relationship. Secondly, the results are also in accordance with our literature review all the previous research conducted regarding internal branding and employee involvement and its impact on emotional intelligence has proven to have a significant impact on our research as well as our results were same as those of previous research conducted.

\section{Conclusion}

Stated below are the points that were concluded from the research: 
1. Employee involvement was positively correlated with the emotional intelligence level of employees in both the organizations.

2. Internal branding practices which were induced in the organizations also had a positive effect on the emotional intelligence level of employees.

Thus, both hypotheses were accepted as there existed a positive relationship between all variables while null hypothesis was rejected.

\section{Recommendations}

In the light of this study it can be recommendated that:

1. Organizations should really work hard on improving their internal branding practices so that employees can be more motivated thus which can cause less stress and frustration resulting in more emotional stability.

2. Managers of the organization should focus more on employee involvement which can lead to more emotional stability within the employees.

\section{Limitations}

1. There were less cooperation from the employees them self. If they would have been more cooperative the results have been more accurate.

2. Less time was there in order for data collection.

3. Data could be analyzed on more advanced analysis tool.

\section{References}

[1] Luker K.A., Austin L., Caress A. \& Hallett C.E. (2000) the importance of 'knowing the patient': community nurses' constructions of quality in providing palliative care. Journal of Advanced Nursing 31(4), 775-782.

[2] Mayer J.D. \& Salovey P. (1993) The intelligence of emotional intelligence.Intelligence 17, 433-442.McMullen B. (2003) Emotional intelligence. British Medical Journal 326(7381), S19.

[3] Brown S.P. (1996). A meta analysis and review of organizational research on job involvement. Psychological Bulletin, 120(2), 235255. doi:10.1037/0033-2909.120.2.235, http://dx.doi.org/10.1037/0033-2909.120.2.235.

[4] Blau G.J. (1985). A multiple study investigation of the dimensionality of job involvement. Journal of Vocational Behaviour, 27, 1936. doi:10.1016/0001-8791(85)90050-8, http://dx.doi.org/10.1016/0001-8791(85)90050-8.

[5] Yang, Hui-Ling, Kao, Yu-Hsiu, and Huang, Yi-Ching (2006). The Job Self-Efficacy and Job Involvement of Clinical Nursing Teachers. Journal of Nursing Research, $\quad$ Vol. $\quad 14, \quad$ No. 3 , 237249.doi:10.1097/01.JNR.0000387582.81845.57,http://dx.doi.org/10.1097/01.JNR.0000387582.81845.57.

[6] Wimalasiri, Jayantha S., and Kouzmin, Alexander. (2000). A comparative study of employee involvement initiatives in Hong Kong and the USA. International Journal of Manpower, Vol. 21 No. 8, 614-634.

[7] doi:10.1108/01437720010379510,

[8] Becker, H. S. 1960. Notes on the concept of commitment. The American Journal of Sociology, 66(1): 32-40.

[9] Liou, K. T., \& Nyhan, R. C. 1994. Dimensions of organizational commitment in the private sector: An empirical assessment. Private Administration Quarterly, 18(1): 99-113.

[10] Scholl, R. W. 1981. Differentiating organizational commitment from expectancy as a motivating force. Academy of Management Review, 6(4): 589-599

[11] Steers, R. M. 1977. Antecedents and outcomes of organizational commitment. Administrative Science Quarterly, 22(1): 46-56.

[12] Walton, R. E. 1985. From control to commitment in the workplace. Harvard Business Review, 63(2): 77-84. 